Relations industrielles

Industrial Relations

\title{
Statistiques et information
}

Volume 5, numéro 3, décembre 1949

URI : https://id.erudit.org/iderudit/1024052ar

DOI : https://doi.org/10.7202/1024052ar

Aller au sommaire du numéro

\section{Éditeur(s)}

Département des relations industrielles de l’Université Laval

\section{ISSN}

0034-379X (imprimé)

1703-8138 (numérique)

Découvrir la revue

Citer cet article

(1949). Statistiques et information. Relations industrielles / Industrial Relations, 5(3), 28-28. https://doi.org/10.7202/1024052ar

Tous droits réservés @ Département des relations industrielles de l’Université Laval, 1949
Ce document est protégé par la loi sur le droit d'auteur. L’utilisation des services d'Érudit (y compris la reproduction) est assujettie à sa politique d'utilisation que vous pouvez consulter en ligne.

https://apropos.erudit.org/fr/usagers/politique-dutilisation/ 
à l'Union internationale des associations patronales catholiques et redit son désir de collaborer avec les autres patrons chrétiens de l'univers pour la réalisation de la doctrine sociale chrétienne.

Elle adresse ses félicitations à l'Association des patrons catholiques d'Italie pour l'éclatant succès du congrès de Rome, en mai dernier.

Elle adhère entièrement aux directives du Saint-Père dans son allocution aux patrons de l'univers, que l'on considère comme le charte des patrons chrétiens.

STATISTIQUES ET INFORMATION

I-ARBITRAGES EN COURS AU 31 OCTOBRE 1949

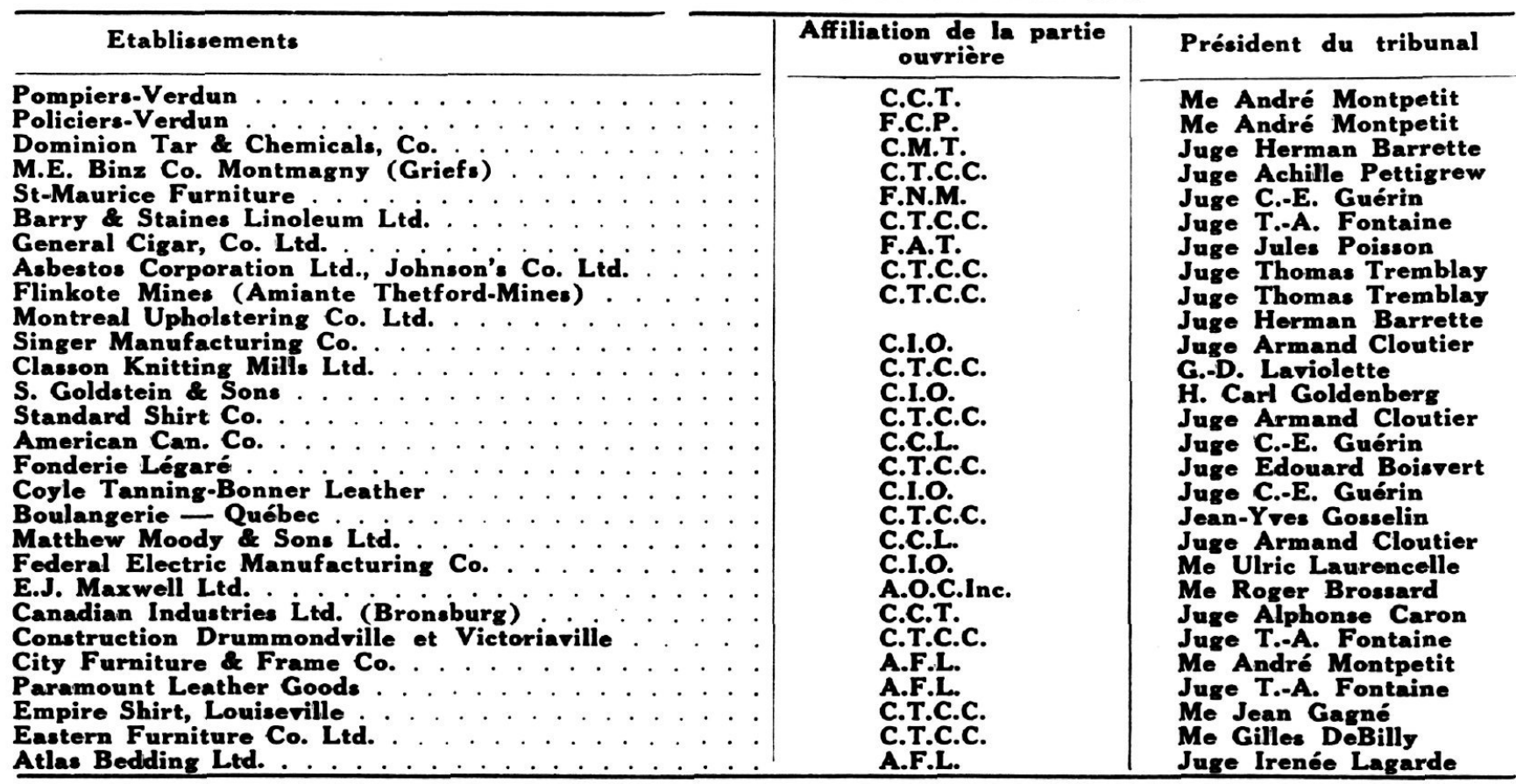

II-SENTENCES RENDUES ENTRE LE ler ET 31 OCTOBRE 1949

\begin{tabular}{|c|c|c|}
\hline Etablissements & $\begin{array}{l}\text { Affiliation de la } \\
\text { partie ouvrière }\end{array}$ & Date de la sentence \\
\hline 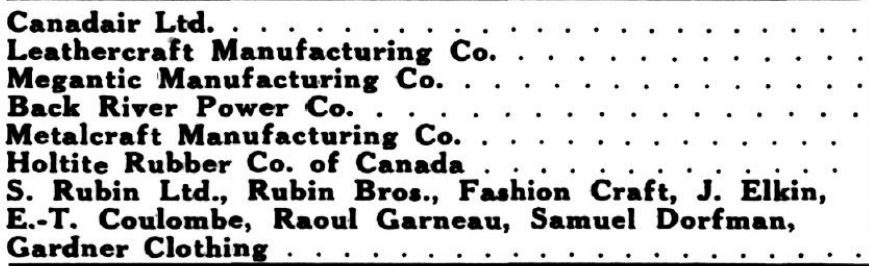 & $\begin{array}{l}\text { C.M.T.C. } \\
\text { F.A.T. } \\
\text { C.T.C.C. } \\
\text { C.T.C.C. } \\
\text { C.I.O. } \\
\text { C.T.C.C. }\end{array}$ & $\begin{array}{r}3-10-49 \\
13-10-49 \\
7-10-49 \\
12-10-49 \\
13-10-49 \\
21-10-49\end{array}$ \\
\hline
\end{tabular}

\section{JURISPRUDENCCE DU TRAVAIL}

Afin de renseigner les lecteurs du Bulletin, le Service de recherches entreprend une chronique mensuelle de Jurisprudence du travail. En principe, cette chronique portera sur les cas courants de jurisprudence soit des cours civiles, comme la Cour Supérieure ou la Cour du Banc du Roi, soit des tribunaux d'arbitrage ou encore sur les décisions intéressantes des diverses commissions administratives provinciales ou fédérales. Il pourra même arriver qu'on étudie des décisions intéressantes des cours étrangères. Bien que notre but soit surtout de nous attacher aux cas courants, il pourra arriver que cette chronique fasse un retour sur le passé afin de présenter aux lecteurs l'analyse de cas qui demeurent, malgré le temps, dune grande actualité. On n'est pas sans savoir, en effet, que la jurisprudence prend ses sources les plus fermes dans des décisions qui datent.

Effet du changement de personnalité juridique des parties à une convention

J.-L. Vachon \& Fils signe une convention collective avec les représentants de ses employés formés en association non incorporée. Après la signature, J.-L. Vachon \& Fils devient J.-L. Vachon \& Fils Ltée, par acte de vente, changeant totalement la personnalité juridique de l'employeur.

D'autre part, l'association non-incorporée devient le « Syndicat du bâtiment et bois ouvré de Beauce \$, incorporé selon la Loi des syndicats professionnels de Québec. Là encore, il y a changement de personnalité juridique. 